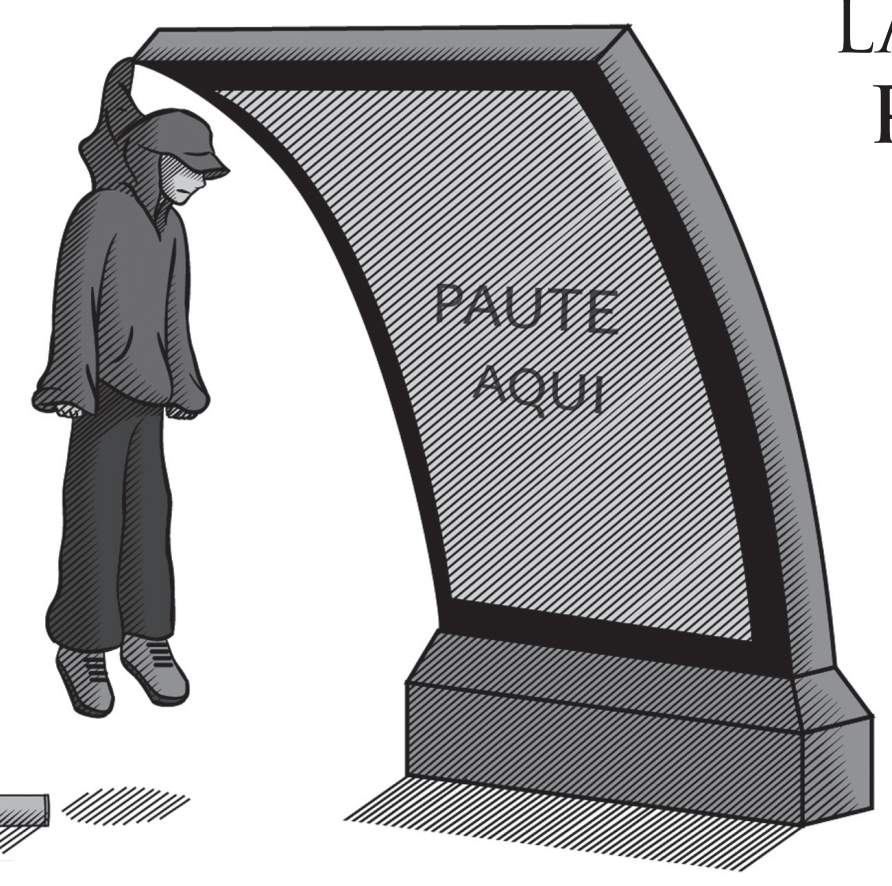

\title{
LA DIMENSIÓN RUTINARIA Y EXTRAORDINARIA DE LA VIDA COTIDIANA EN LA CIUDAD
}

\author{
THE ROUTINE AND SPECIAL \\ DIMENSION OF EVERYDAY LIFE \\ IN THE CITY
}

Por:

\author{
Diana Castelblanco ${ }^{1}$ \\ Universidad Jorge Tadeo Lozano, Bogotá. \\ diana.castelblanco@utadeo.edu.co \\ Colombia
}

Resumen: Aún cuando el conocimiento que se ocupa de los estudios urbanos tiende a especializarse desde muchas áreas académicas, hace un tiempo relativamente reciente (cinco años aproximadamente), existe una notable preocupación de las áreas derivadas del diseño, en particular del diseño industrial, por aproximarse a la ciudad, ya no solo desde las intervenciones técnicas que por defecto son acción disciplinar, sino también desde interpretaciones estéticas y políticas que den cuenta de la complejidad social contemporánea y, en consecuencia, que coincidan con estudios derivados de las teorías fenomenológicas, de la complejidad o los estudios culturales, entre otros.

El diseño, como paradigma trascendental de las transformaciones suscitadas por los procesos de modernización ${ }^{2}$ de las ciudades, también hoy es motivo para cuestionar y debatir su rol en tanto los problemas de las interacciones ciudadanas mediadas por los artefactos; la producción de intersubjetividades como resultado de las experiencias condicionadas, determinadas, pero también casuales y espontáneas que se producen entre los agentes vitales de la ciudad, la construcción de significados sobre las percepciones que suscitan dichas experiencias en sintonía con la cultura material; la ciudad más que como un espacio geométrico y físico, como un espacio donde se representan acontecimientos urbanos que descansan en estructuras técnico-estéticas, entre muchas otros fenómenos de actualidad de la vida cotidiana. El presente documento se propone indagar sobre las reflexiones contemporáneas que desde el Diseño se aproximan a tal propósito de pensar la ciudad y en especial pensar los asuntos del desarrollo desde una perspectiva política y social de la cultura material. 
Palabras clave: Diseño, vida cotidiana, ciudad, técnica, política, estética.

\begin{abstract}
Although the knowledge that addresses urban studies tends to specialize from many academic areas, makes a relatively recent ( 5 years or so), there is significant concern arising areas of design, including industrial design, to approximate the city and not only from the technical interventions that are default disciplinary action, but also from aesthetic and political interpretations that account for contemporary social complexity and, consequently, matching studies derived from phenomenological theories, complexity or cultural studies, among others. The design, as transcendental paradigm of transformations resulting from the modernization of cities, today is also reason to question and discuss its role in both the problems of citizen interactions mediated by artifacts; intersubjectivities production as a result of conditioned experiences, determined, but also casual and spontaneous that occur between vital agents of the city, the construction of meanings on perceptions that raise these experiences in tune with the material culture, the city rather than a geometric space and physical as a space where urban developments are represented structures that rely on technical and aesthetic, among many other current phenomena of everyday life. This paper proposes investigate contemporary reflections from the design approach of thinking this purpose the city and especially thinking development issues from a political and social perspective of material culture.
\end{abstract}

Keywords: Design, everyday life, city, art, politics, aesthetics

\title{
Introducción
}

El presente texto se orienta en torno a cinco enunciados que hoy pueden, provisionalmente, ser aproximaciones discretas para refutar, contrastar o verificar la relación que los diseñadores establecen con la ciudad contemporánea y el resultado que, fruto de esta relación en términos de productos técnicos, estéticos y políticos, ya no es sometido solo a pruebas científicas, técnicas, físicas y en general lógicas, sino a rigurosos experimentos y observaciones sociales y sensibles. Necesariamente vinculan al profesional del diseño como uno más de los productos de diseño -si se quiere decir-, que también ha de pensar su rol activo como ciudadano y técnico social.

Desde cada enunciado se cuestionan posturas que parecieron incuestionables en el diseño, la mayoría relativas a la producción técnica, funcional y formal de los productos como propósito último, para pensar si acaso la complejidad del mundo de hoy no demanda también complejizar la perspectiva fundacional de la disciplina.

1. El diseño como conocimiento social.

No es un problema de las formas sino de la vida cotidiana de los hombres

2. El diseñador es ciudadano y el ciudadano diseña.

No es producto de la erudición del profesional. Es conflicto y negociación entre los habitantes. 
3. El diseño se debate entre la razón técnica y la razón sensible.

No tiene como fin la producción de piezas concretas, sino la creación de lenguajes, experiencias y cartografías que vuelvan inteligibles los mensajes críticos y reflexivos.

\section{El diseño produce formas.}

No son estables, inmutables ni certeras. Son inciertas porque están abiertas a las transiciones técnico-tecnológicas de la sociedad.

5. El diseño es un ensayo.

No busca conclusiones y celebra los errores.

Voy a partir de una premisa simple: la ciudad es un escenario próspero para las acciones de diseño en la sociedad contemporánea. Desde luego esta premisa tiene implícitos problemas de orden mayor que no pretendo resolver, pero sí ingenuamente mencionar para encumbrar con ellos algunas situaciones de facto que circulan en el diseño hoy.

De hecho la premisa misma no se refiere a otra cosa más que al interés -pareciera reciente- de los diseñadores para actuar en la ciudad y escudriñar con sus prácticas en los fenómenos que determinan la vida social contemporánea. En una aproximación general, se entiende fenómeno como "toda manifestación que se hace presente a la consciencia de un sujeto y aparece como objeto de su percepción" (Real Academia Española de la Lengua -RAE-). En este texto entonces, los fenómenos contemporáneos son un interés por la apariencia (de "lo que se aparece", no de lo que se aparenta) o el fundamento del saber empírico de los acontecimientos urbanos que rodean la propia existencia de los profesionales del diseño. Entre los diseñadores este interés provoca un "modo de ver" y un método, que en coherencia con la práctica misma del diseño, busca asimilar la idea que la abstracción, el juicio, o la inferencia nunca serán actos empíricos, sino que nacen de una intencionalidad: El Proyecto de Diseño.

\section{El diseño como conocimiento social}

Un mundo cambia constantemente y a un ritmo impredecible; tensiones, diferencias y contradicciones entre los valores declarados y las prácticas sociales; extremos de barbarie en medio de la civilización; identidades que se intentan reafirmar pero que inexorablemente se transforman; el mito de volver a la naturaleza como un rechazo a la sociedad occidental, sin embargo, la montaña hoy es un recurso industrialmente aprovechable; defensas por la diferencia cuando muchos son indiferentes; pretensiones de igualdad social en medio de desigualdades históricas; normas sociales impuestas y sacralizadas que se emancipan del poder político pero se esclavizan al poder económico; tiempos de ocio que hoy son tiempos de consumo; vivencias íntimas que se insertan como patrimonio colectivo; profesiones, como el diseño, que ya no se explican en 
función de un determinado sistema de división social del trabajo, sino desde problemas fundamentales a cualquier estructura social. Estos, entre muchos otros fenómenos, parecen hoy de interés para los diseñadores.

Me gusta recordar al escritor uruguayo Eduardo Galeano, quien en entrevista para el periódico digital español Público (2010) sugiere los siete pecados capitales del mundo contemporáneo, que bien ahora me sirven para situar lo que llamo "el estado del mundo" y al final pensar que entre los diseñadores se habría de esconder una actitud morbosa para escudriñar en ellos: (1) el racismo: no solo referido a una cuestión de piel: "la guerra de Irak también es racismo" dice Galeano; (2) la tradición machista: aún siendo femeninos los símbolos de las victorias de los derechos ciudadanos en la Revolución Francesa, las mujeres que buscaron reivindicar sus derechos fueron aniquiladas; (3) la intolerancia al diferente: se reclama hoy la legalización del matrimonio homosexual; (4) el desprecio al trabajo: dice el autor que "las jornadas de trabajo se miden con los relojes derretidos de Salvador Dalí [...], es el precio lo que fija el valor y no al revés”; (5) el mundo miente: la comunicación ahora es manipulada por los medios y curiosamente los hechos en torno al muro de Berlín merecen informarse "más y diferente" a los hechos que hoy son noticia en la frontera en México, Cisjordania o el Sáhara Occidental. (6) el mundo mata: la paz mundial está en manos de quienes producen las armas. (7) el mundo fabrica enemigos: "y lo hace a través del miedo. La democracia tiene miedo a recordar, las armas tienen miedo a la falta de guerra y los hombres tienen miedo a la mujer sin miedo".

En estos tiempos proliferan los análisis al respecto, y cabe afirmar que no son pocas las ambivalencias que emergen con relación a las nociones de vida, progreso, bienestar, etc., que reflejan los extremos de la peor condición del hombre contemporáneo y las bondades del momento cultural actual: la prolongación de la esperanza de vida, la disminución de la mortalidad infantil, cuotas incrementales en la educación universal, difusión y reconocimiento público de la democracia y los derechos, y en general logros como el avance científico y tecnológico.

Ante la imposibilidad de reproducir esta complejidad, es común encontrar que los diseñadores se nieguen a la positivación de la sociedad, luchando cada vez más con las ideas sobre la funcionalidad de los procesos, las prácticas, los productos, y ocupándose mejor de la reflexión sobre las razones y los sentidos que permiten la existencia de los mismos y el contraste entre los logros de la civilización y las aberraciones de la barbarie. Esta idea es complementaria a la última revisión de la definición de diseño industrial del ICSID (Concilio Internacional de Asociaciones de Diseño Industrial) que dice: El diseño trata de descubrir y valorar las relaciones estructurales, organizativas, funcionales, expresivas y económicas con la misión de ofrecer:

- ETICA GLOBAL:Mejorar la sostenibilidad global y la protección del medioambiente. - ETICA SOCIAL: Ofrecer beneficios y fomentar la libertad de la humanidad, sea de forma individual o colectiva.Velar por los intereses de los usuarios, de los productores y de los protagonistas del mercado.

- ETICA CULTURAL:Velar por la cultura a pesar de la globalidad impuesta. 
De allí que el diseño en sociedad adquiere un estatus inagotable en tanto es un acto pedagógico -de conocimiento- sobre la(s) realidad(es), que necesita del sujeto (del otro) para alimentar los procesos de creación que dan cuenta de las reflexiones sobre el estado del mundo.

El diseño como acto pedagógico se apoya en la producción de experiencias, artefactos o interacciones, para interpretar las prácticas sociales y revelar, cuestionar o transformar aquello que pueden ser los pecados del mundo contemporáneo. En este escenario, parece ser determinante la relación entre los estudios antropológicos, sociológicos y otros derivados de las humanidades, con los estudios de diseño, si acaso hoy el diseño ya no es solo un problema exclusivo de la forma y si mejor de la vida cotidiana de los hombres. El diseño se descentra de aquel conocer técnico, productivo y funcional y se localiza en un conocer, fruto de las experiencias suscitadas en la vida social, que se cargan de memorias y deseos sobre los acontecimientos, los lugares, los artefactos y demás expresiones sensibles, que caracterizan las prácticas del hombre contemporáneo, con sus particularidades sociales, culturales, políticas, económicas, medio ambientales, etc. Como las que describe Galeano (2010), o, por qué no, otras como las que narra Antonio Muñoz Molina en su libro Fragmentos de Manhattan (2004). Molina recorre fragmentos de vida de personajes en Nueva York, que no solo ejemplifican la condición particular y exquisitamente sensual de la ciudad con relación a cómo interactúan los estímulos sensoriales sobre el cuerpo humano, sino que también dan cuenta de un conocimiento estético que se produce gracias a la asociación entre las ideas y la imagen de la ciudad.

[...] la embriaguez del olfato es tan excitante como la del oído o la de la mirada, y el olor de pan caliente de una tahona sucede al de una pizzería y al de una lavandería, que es uno de los olores decisivos de Manhattan, olor a tela húmeda y caliente y al vapor de las secadoras, tan omnipresente como el de la pizza, el de los pretzels tostados, los perritos calientes y las fritangas de los puestos callejeros; como el olor cálido y denso que sube de los respiraderos del metro. Los cinco sentidos, como en las alegorías de Brueghel, los siete pecados capitales, las potencias del alma, el ritmo de los pasos y el de la respiración, los latidos del corazón que no se escuchan y sin embargo lo van manteniendo a uno vivo y erguido en medio de la multitud, caminando, escuchando, mirando, oliendo, tocando. (Muñoz, 2005, p. 178 citado en Garrido, 2007, p. 189)

[...] el paseante de las grandes urbes europeas del XIX monopolizaría el privilegio de su sensibilidad perceptiva para producir no sólo género literario, sino también pintura, ilustraciones, periodismo, novela, narraciones breves, estudios fisiológicos, ensayo y mucho debate sociológico (Garrido, 2007, p.182).

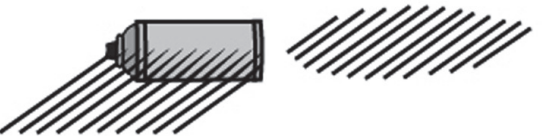


Hoy el diseñador potencia sus sentidos y reconoce los sentidos del ciudadano como una manera para aproximarse a sus mundos y sintetizarlos en un diseño que se ligue más que al mundo de las mercancías, al mundo de los productos sensoriales.

\section{El diseñador es ciudadano y el ciudadano diseña}

La embriaguez del diseñador es la misma del paseante en la ciudad que se alimenta de lo que a éste se le presenta sensiblemente en su viaje. Cada cosa se da al ciudadano como una vivencia y es él quien "le saca su color". Aquí se crea la producción del sentido, una expresión del diseño como acto pedagógico fruto de un conocimiento estético, de la sensibilidad social que se impone desde las condiciones del observador. Un conocimiento que reside en las diferentes estéticas de los ciudadanos-diseñadores y que se encuentra en un estado de permanente conflicto y negociación. Un conocimiento inacabado. Como dice Garrido "para aquellos que no entiendan, un verso de Pablo Neruda: Nunca te detuviste a mirar los pequeños signos atraídos en las calles" (Garrido, 2007).

El diseño aquí aparece como fruto de la diversidad de las relaciones sociales que se dan en cualquier espacio habitado; es un fenómeno de interacción que se construye y re-construye en la vida social. El diseño es producto de la intersubjetividad del hombre contemporáneo. Mientras la subjetividad supone la conciencia que se tiene del mundo desde un punto de vista propio, la intersubjetividad permite compartir esos conocimientos y construir significados de manera colectiva sobre aquello que se percibe, se imagina y se hace. Desde esta perspectiva el diseño es parte de los fenómenos de la vida contemporánea: el diseñador es ciudadano y el ciudadano diseña productos dinámicos e inacabados, que representan las intersubjetividades propias de los habitantes urbanos. El diseño en la ciudad parece entonces ser producto de la construcción colectiva del sentido, y ya no solo de la interpretación erudita de un profesional.
La intersubjetividad en las relaciones de un parque público se reconstruye constantemente en tanto se dinamizan los acontecimientos que se dan en el lugar y en consecuencia los actores que participan de dichas prácticas. Recreación y deporte, arte y cultura, servicios y productos, son ejemplos de los pequeños sistemas sociales que se dan un parque. Este proceso intersubjetivo esta mediado por las diferentes formas de percibir del ciudadano-diseñador (que cambian según el fenómeno que en el lugar suceda); de imaginar (las ideas se modifican) y de actuar (las prácticas y comportamientos también cambian). (Castelblanco, 2010)

\section{El diseño se debate entre la razón técnica y la razón sensible}

Se puede considerar que hay una reconstrucción de la racionalidad instrumental del progreso en tanto las invenciones socio -técnicas y socio estéticas (Maffesoli, 1997), no solo pensadas como productos sino como procesos que se originan desde los modos de ver del ciudadano-diseñador, son quienes se encuentran en ese estado permanente de conflicto y de negociación. La razón técnica por un lado defiende las ideas de modernidad vinculadas con las ciudades metropolitanas, donde a las prácticas urbanas se les otorga un carácter puramente funcional que, dice John Friedmann (1986), necesariamente polarizan las clases sociales como una consecuencia directa de la economía global y de la división del trabajo. La razón sensible por su lado problematiza la estructura y dinámica productiva global, que en las ciudades metropolitanas irremediablemente provocan una suerte de segregación socio-espacial, en tanto están territorialmente dispuestas desde centros financieros y emporios de consumo internacional. 
La técnica es un producto social que tiene por propósitos ejercer una modificación sobre el ambiente, archivar esta modificación y convertirla en experiencia y conocimiento. La memoria técnica en últimas se configura como historia. El diseño es memoria técnica y si acaso todo hecho técnico en la ciudad participa de los marcos sociales que regulan las prácticas de sus habitantes, la técnica es causa y consecuencia del ordenamiento y control ciudadano. La técnica es una estrategia colectiva para definir territorios y para ejercer acciones en él, muchas de ellas ceñidas por un principio de exclusión. La técnica actúa como parte del ejercicio del poder sobre el territorio, el ejercicio de la dominación de un grupo sobre otros, gracias a que delimita y fortifica los lugares. Dice Félix Duque (2001) que si bien el espacio es producto de la técnica, ello se debe a que ésta es eminentemente política.

La técnica puede motivar el ejercicio de la violencia y de la dominación, así como la dificultad para la convivencia en comunidad, de allí el conflicto social sobre el uso del territorio en la ciudad. Por esta razón, la técnica demanda de un marco ético, asociado a la participación igualitaria de valores y de experiencias, para compensar la desigualdad con la virtud política de la justicia. (Castelblanco, 2010, p. 45)

El diseño se debate entre la razón técnica y la razón sensible cuando se reconoce que a través del tiempo ha sido una expresión social que da cuenta de un aparente estado de bienestar de la gente en la ciudad, y por tanto un medio para que en la actualidad vehicule lo que se ha dado por denominar la imagen de la ciudad (Lynch, 1966) o la ciudad ficción de Marc Augé (1999). Las condiciones históricas revelan una dependencia del diseño con expresiones de bienestar vinculadas al buen gusto y a la estética; ambas asociadas a algún tipo de ideas de cultura que reproduce fielmente los valores de la ciudad. Bajo esta perspectiva, el diseño en la ciudad es signo de distinción, pero inevitablemente y, en consecuencia, también es signo de segregación social.

Los parques de entretenimiento, los clubes de vacaciones, los parques de ocio-descanso y de residencia como los Center Parks en Europa, pero también los barrios privados y las ciudades privadas que surgen más y más numerosas en América, y hasta estas residencias fortificadas y protegidas que se elevan en todas las ciudades del tercer mundo como castillos, constituyen eso que podríamos llamar burbujas de inmanencia. Encontramos todavía otras burbujas de inmanencia, por ejemplo las grandes cadenas hoteleras o comerciales que reproducen poco o mucho el mismo decorado, destilan el mismo tipo de música a través de sus estantes o en sus ascensores, difunden los mismos video-films y proponen los mismos productos fácilmente identificables de un lado del planeta. En el fondo las burbujas de inmanencia son el equivalente ficcional de las cosmologías. (Augé, 1999, p. 244) 
En la ciudad ficción, "la ficción se apodera de la realidad y la distinción entre lo real y lo no real se vuelve opaca, borrosa; se vive de imágenes recibidas a través de los mass-media en un aislamiento que aumenta el "efecto de insularidad" y desarrolla la circularidad pregnante de la ciudad premoderna convirtiéndola de nuevo en un elemento de distinción y de división (Popeanga, 2010).

Con lo anterior se advierte por un lado cierta estrechez del dominio técnico que el positivismo científico propone, siendo éste la base ideológica del capitalismo avanzado; por otro lado, se señala que la complejidad creciente del sistema social no puede reducir al diseño a una descripción del mercado y de los instrumentos estratégicos institucionales que lo legitiman; de allí la pregunta sobre qué tan valioso es para el diseñador no solo aproximarse a las prácticas cotidianas para entender la complejidad del sistema social, sino reconocer que es parte y protagonista de ellas, y cuáles habrían de ser los referentes sensibles que verifican su conocimiento sobre estas prácticas.

Hay casi que una revolución de la razón sensible frente a la razón técnica, que valora las experiencias, los deseos y las memorias urbanas de los ciudadanos, pero que también se compromete con el análisis y la crítica sobre las decisiones públicas que afectan las maneras de vivir en el mundo de hoy. El abordaje del mundo contemporáneo sugiere miradas holísticas que contrasten las tradicionales formas de concebir el desarrollo social y económico desde la perspectiva modernista. Michael Maffesoli (1997) en su texto Elogio de la razón sensible, una visión del mundo contemporáneo, subraya la necesidad de articular al conocimiento analítico, el pensamiento intuitivo, vivencial y en general el conocimiento sensible para visualizar y comprender los fenómenos sociales y considerar la vida en su conjunto.

\section{El diseño produce formas}

En últimas hay tal apertura disciplinar (propia de los modelos contemporáneos del conocimiento) que el imaginario industrial de los siglos XX y XXI ya no solo se organiza en torno a la producción material y al trabajo: hoy se habla de intangibles y de conceptos, de sociedad de la información y sociedad del conocimiento. El diseño deja de ser un medio para la producción de piezas concretas, y pasa a ser medio para la creación de lenguajes, experiencias y cartografías que vuelvan inteligibles los mensajes críticos y reflexivos. Todo un mundo de oportunidades para el diseño

de productos, imágenes

y en general para la construcción del paisaje cultural urbano. 
En estas búsquedas, si bien el diseño en la ciudad se encuentra con disciplinas sociales, mantiene el hecho de tener que producir formas que se reconcilien con los lenguajes característicos de la sociedad contemporánea. Lenguajes que parecen ya no definirse desde una esencia inmutable sino desde una esencia histórica que depende de las transformaciones sociales y del desarrollo de la tecnología. En estos tiempos el diseño termina siendo tan inestable como inestables son los vínculos sociales que invariablemente han estado condicionados a las transiciones técnico-tecnológicas; lo cierto es que hoy estas transiciones suceden a una velocidad incompresible para muchos, pero esperada por otros porque simuladamente garantizan lo actual y renovado del diseño. Las transformaciones sociales proponen nuevas expresiones estéticas cada día más dependientes de las tecnologías emergentes; esto resulta interesante para afirmar, a manera de hipótesis, que el diseño es tan incierto en tanto las nuevas tecnologías ya no dan certeza.

La indeterminación e incertidumbre además de engañar a los sentidos, dejan abiertos los productos de diseño (experiencias, artefactos, interacciones, servicios, imágenes), para que las personas experimenten no propiamente con el producto mismo, pero sí con las prácticas de la vida social donde aquel tan solo es medio, nunca será fin.

Este panorama seguramente propone discutir con más firmeza los paradigmas tradicionales sobre los cuales se fundan las acciones del diseño, y las formas de legitimarlo socialmente, lo que probablemente dejó de ser novedoso hace varios años, pero sí por lo menos sigue siendo necesario para comprender las contradicciones que lo albergan y que hoy motivan a celebrar su incertidumbre, -la del diseño-, como un valor estructural que lo mantiene vigente dentro de los acelerados procesos de transformación social de la vida contemporánea en la ciudad.

La incertidumbre en el diseño de hoy habita incondicionalmente en las interacciones ciudadanas mediadas por artefactos: es la incertidumbre del diseño en las prácticas urbanas; habita en la producción de experiencias unas veces casuales y espontáneas, otras más determinadas y condicionadas: es la incertidumbre en la sensibilidad ciudadana; finalmente habita en la construcción de significados sobre las percepciones que suscitan las experiencias urbanas en sintonía con la cultura material: es la incertidumbre sobe el sentido y el conocimiento de la ciudad.

Las personas hoy tienen una relación ambivalente con aquella idea de la completa resolución del diseño, la precisión y exactitud técnica, estética, funcional y productiva, que declara la conclusión inequívoca del producto. Desde luego esto no se refiere a que el diseño se aleja de la necesidad de usar ideas probadas en Física, Química o Biología, ni tampoco de ver y medir aquello que es estrictamente necesario. El diseño como fenómeno cultural no está exento de explicaciones científicas, genéticas, neurofisiológicas y otras derivadas de las ciencias matemáticas basadas en el funcionamiento cerebral y en las interacciones físicas mediadas por el lenguaje. Sin embargo, ¿cuántas cosas acaso no se mantienen abiertas y disponibles para ir en múltiples direcciones y reconfigurar nuevas situaciones? 
Puede ser este uno de los tantos debates abiertos que reafirman el afán intelectual de muchos (mío) por aproximarse a unas -otras- nociones del diseño industrial que, desde luego obligan a repasar aquellas que fueron fundacionales, y que en las últimas décadas se amparan del ICSID como ideas más o menos "oficiales” y unificadoras de lo que se entiende por diseño industrial. Sin embargo, lo perfecto e invariable en el diseño resulta sospechoso, en tanto niega la posibilidad del cambio intrínseco de una profesión que declara ponerse al servicio de las necesidades humanas.

\section{El diseño es un ensayo}

La propuesta de la ciudad como un escenario próspero para las acciones de diseño en la sociedad contemporánea radica entonces en abordar las interrelaciones que se dan alrededor de las expresiones del diseño, más que en abordar el fenómeno mismo del diseño, para hipotéticamente decir que si bien un producto de diseño puede estar en la línea de lo concreto, lo abstracto, lo experimental o lo aplicado, los vínculos sociales que emergen de cualquiera de estas expresiones, están en las fronteras de lo desconocido y de lo impreciso.

En las fronteras del ensayo

El diseño en la ciudad entonces se convierte en una búsqueda incesante por el error y el ensayo. Desde una mirada amplia parece que el diseño hoy tiende a rechazar las conclusiones y en cambio tiende a favorecer la repetición y el ajuste permanente en busca de una inexistente precisión. Desde el diseño y la estética, replicando las palabras de Russell Ferguson, curador de la exposición Política del ensayo, de Francis Alÿs (2009), se trata de poner la idea del ensayo en el centro de la práctica. Así como para un director de teatro el ensayo es el momento específicamente creativo, "allí él esboza, borra, repentiza, suscita”, para un diseñador cada ensayo terminado es el preámbulo a situaciones, ocasiones o encuentros sociales indeterminados (Goffman, 1979, citado en Wolf, 1994, p. 28), justo por la incertidumbre que se esconde en las relaciones sociales, que a decir de Turner (1988), jamás son lógicas y están llenas de contradicciones y conflictos. El teatro es a la ciudad como el director al diseñador. En ambos casos el nivel en el que operan los diferentes impulsos y talentos de los participantes (actores-ciudadanos), no importando que tan dictatorial pueda ser el compositor (director-diseñador), siempre estará mediado por un elemento de colaboración como parte integral del tránsito desde el ensayo hasta la obra terminada.

Lo inacabado del diseño y su estado permanente de ensayo, garantizan una iteración más en la que las cosas pueden ser distintas. Este proceso significa que el momento de la culminación del diseño está siempre potencialmente pospuesto, se difiere, se aplaza y se proyecta de alguna forma hacia el futuro, "un futuro que avanza invariablemente por delante de la obra” (Ferguson, 2009). Entre tanto, cada episodio social hace que la presencia del diseño pueda cambiar permanentemente de forma, no sólo como expresión física sino como experiencia de conocimiento sensible de las prácticas sociales. 
El diseño hoy, así como los fenómenos, no se define desde la apariencia (lo que se aparenta) o desde la lógica de lo formal, tampoco desde lo que son o lo que no son las cosas. Hoy el diseño se aproxima más a una definición desde el conflicto, fruto de la contradicción, donde el diseñador deja de ver la armonía, piensa dialécticamente, piensa el fenómeno y el reflejo de lo que está por dentro del proceso. El diseñador hoy ve el fenómeno como un proceso que está en constante cambio y sabe que su trabajo, inacabado por cierto, -de allí el encanto del ensayo-, está en descubrir el porqué del cambio. Apostarle a la crítica como una posibilidad de transformar el orden que previamente estaba construido.

Las propiedades necesarias, objetivas y suficientes del diseño ya no son lo que eran. Ahora hay unos hechos imprecisos, tenues y periféricos que revelan metafóricamente su carácter incierto y ponen en evidencia los imaginarios, las poéticas y voluntades de la gente. El diseño ya no se preocupa por provocar cosas: ahora provoca eventos y en consecuencia es una narración que define un espacio, un tiempo, una escena, unos personajes, un motivo, unos referentes y un estilo.

El diseño es un punto de partida para una nueva obra, donde se reconfigura técnica, productiva y estéticamente el significado y el sentido de su presencia. Lo interesante es cómo esta presencia indeterminada, contradice los preceptos de la homogeneidad del mundo global, en tanto que cuando el diseño aparece en nuevas situaciones lo más probable es que resulte produciendo de igual forma nuevos efectos que descubren la dimensión rutinaria y extraordinaria de la vida cotidiana en la ciudad.

\section{Discusión:}

A manera de ensayo sobre una posible conclusión que se aplaza y se proyecta hacia el futuro:

\section{El diseño como conocimiento social}

El diseñador ha de ser un hombre de mundo, con mirada curiosa e interés vivo en la ociosidad, para descubrir lo cotidiano de la ciudad. De allí que acuda al sentido alegórico del flaneur que deambula sin rumbo por los pasajes de París. Su misión, como el flaneur, es encarnar nuevos modelos de percepción que se resistan a la alienación de las multitudes. Esto implica que el diseñador asuma una postura comprensiva y crítica sobre los pecados del mundo contemporáneo y en general sobre el mundo de las mercancías que la vida cotidiana de cualquier transeúnte se resiste a abandonar.

\section{El diseñador es ciudadano y el ciudadano diseña}

El diseño es la expresión extraordinaria de una experiencia ordinaria, pura e inútil, que representa la multitud con regocijo. Representan la dimensión rutinaria y extraordinaria de la vida cotidiana, por lo cual se propone un tipo de diseñador-ciudadano- que se aproxima a la cotidianidad de un personaje, a su propia cotidianidad y reconoce desde él la complejidad socio cultural de las prácticas sociales contemporáneas. 
3. El diseño se debate entre la razón técnica y la razón sensible

El diseñador caracteriza la experiencia perceptiva de los sentidos de su personaje, de sus sentidos, para construir un discurso sensorial que descubre el placer y sus deseos más velados. De allí que incorpora la estética como estímulo positivo, evocador, alusivo, reminiscente, necesario para el hombre. Complementariamente reconoce la dimensión espacial de la ciudad y define la territorialidad como producto de una práctica social mediante el cual su personaje, él, declara característicamente sus pretensiones en una extensión del espacio. Para esto proporciona el marco dentro del cual se hacen las cosas: lugares para aprender, lugares para jugar, lugares para servir.

\section{El diseño produce formas}

El diseñador caracteriza un determinado orden que no solo se refiere a colocar certeramente figuras para optimizar las relaciones entre ellas, sino a optimizar las prácticas de la vida social, garantizando el movimiento continuo de la composición y su adaptación a los múltiples públicos ciudadanos. Reconoce que las técnicas que garantizan la forma, en la ciudad pierden su capacidad de certeza, pero ganan capacidad estética, de allí que no necesariamente busca la comprensión, dado que el diseño mismo busca no agotarse. Ahí radica la permanencia estética: no se encuentra en el objeto sino en el sujeto ciudadano-diseñador.

\section{El diseño es un ensayo}

El diseñador analiza los episodios sociales en la ciudad (Goffman, 1994) que acontecen entre los tiempos de ocio, los tiempos productivos y los tiempos de consumo, como grandes enigmas de la vida contemporánea, y distingue entre las cosas que se viven mecánicamente y las que exigen creatividad permanente.

\section{Notas}

\footnotetext{
${ }^{1}$ Diseñadora Industrial, Especialista en Gerencia de Diseño y Magister en Hábitat. Docente del Departamento de Estética de la Universidad Javeriana. Co-Fundadora del estudio de diseño ENLACE DISEÑO Ltda. y diseñadora asociada de Estudio PIGMA DISEÑO. Desde 2002 docente, investigadora y directora de proyectos de grado de las universidades Javeriana y Jorge Tadeo Lozano, en áreas de estética, diseño y hábitat. Actualmente, coordinadora académica, docente e investigadora del Programa de Diseño Industrial de la Universidad Jorge Tadeo Lozano. Grupo de Investigación Diseño, Pensamiento, Creación. Líneas de investigación Historia, Sociedad y Cultura / Territorio, Ciudad y Arquitectura.

2 "La globalización conlleva la radicalización de la modernidad. De ahora en adelante nos enfrentamos a un cierto tipo de modernidad para siempre y en todas partes, tal como lo plantea la posición liberal progresista o la tercera vía, con teóricos como Giddens, Touraine, Castells, Habermas (con diferentes implicaciones sobre como "completar" el proyecto moderno para cada uno de estos pensadores). Escobar, A. Globalización, Desarrollo y Modernidad. (En: Organización de Estados Iberoamericanos para la Educación, la Ciencia y la Cultura. http: / / www.oei.es/salactsi/escobar.htm) Publicado en: Corporación Región, ed. Planeación, Participación y Desarrollo (Medellín: Corporación Región, 2002, pp. 9-32).
} 


\section{Referencias}

Arendt, H. (1977). Qué es la Política? Barcelona, España: Paidós.

Augé, M. (1998). El viaje imposible, el turismo y sus imágenes. Barcelona, España: Gedisa.

Bachelard, G. (2000). La Poética del Espacio. México: Fondo de Cultura Económica.

Berger, P; Luckman, T. (1979). La Construcción Social de la Realidad. Buenos Aires, Argentina: Amorrortu. (pp.162-163).

Castelblanco, D. (2010). Los Relatos del Objeto Urbano: Una reflexión sobre las formas de habitar el espacio público. Bogotá, Colombia: Punto Aparte. Universidad Nacional de Colombia.

Certau, M. (2000). La invención de lo cotidiano. Vol.2, Habitar, Cocinar. México: Universidad Iberoamericana. Departamento de Historia. Instituto Tecnológico y de Estudios Superiores de Occidente: Cultura Libre.

Duque, F. (2001). Arte Público Espacio Político. Madrid, España: Akal.

Featherstone, M. (1991). Cultura De ConsumoY Postmodernismo. Amorrortu Editores.

Friedmann, J. (1986). TheWorld City Hypothesis. Development and Change. vol. 17, p. 69-83.

Goffman, E. (1994). Relaciones en público. [aut. libro] Mauro Wolf. Sociología de la vida cotidiana. Madrid, España: Cátedra.

Lynch, K. (1966). La imagen de la ciudad. Buenos Aires, Argentina: Infinito.

Lliovet, J. (1981). Ideología y Metodología del Diseño. Barcelona, España: Gustavo Gili. (pp.12).

Martin, J. (2002). Contribuciones para una antropología del diseño. Barcelona, España: Gedisa.

Mafessoli, M. (1997). Elogio de la Razón Sensible. Barcelona: Ediciones Paidós.

Muñóz, A (2004). Fragmentos de Manhattan. Buenos Aires: Seix Barral.

Santos, M. (1998). La Naturaleza del Espacio. Técnica y tiempo. Razón y emoción. México : Ariel S.A.

Wolf, M. (1994). Sociología de la Vida Cotidiana. Madrid, España: Cátedra S.A. (pp 23-27).

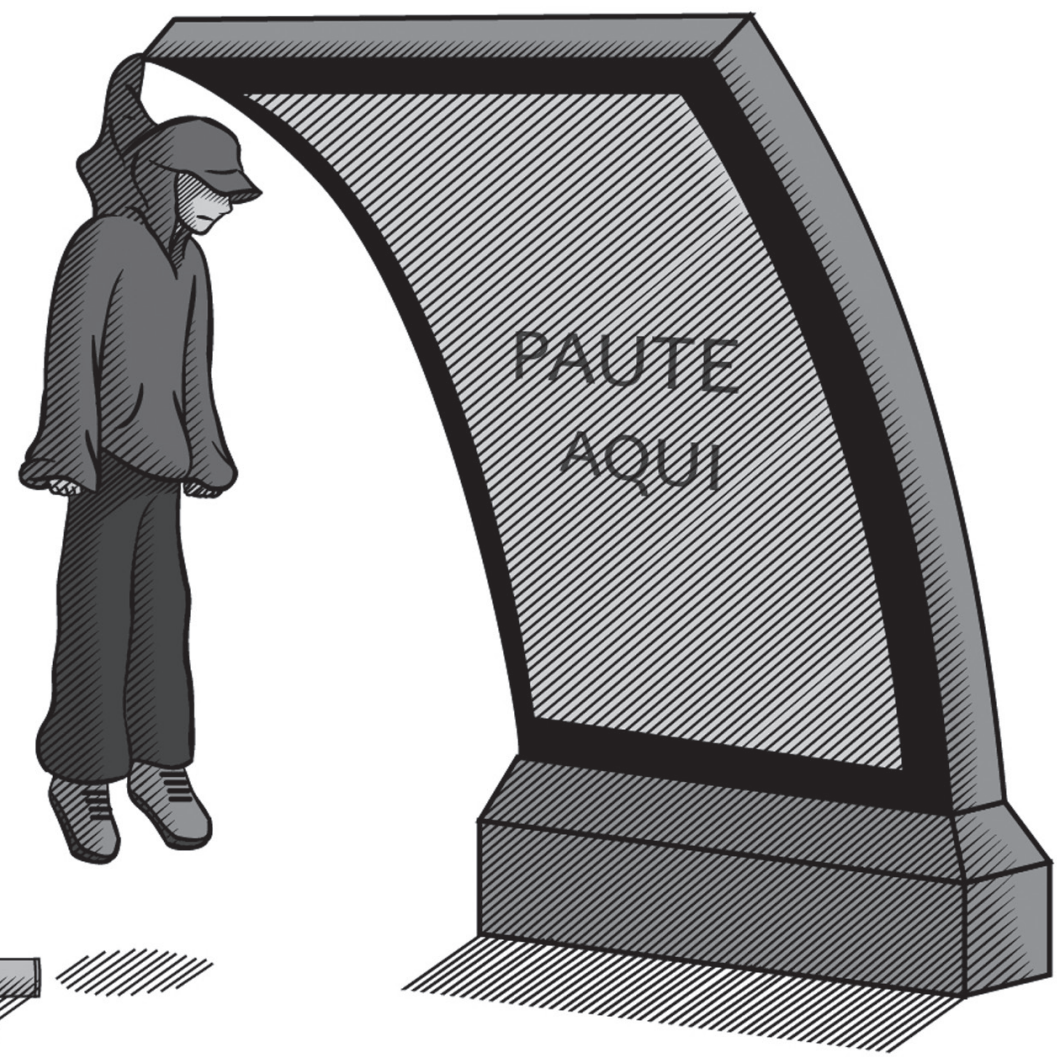




\section{Revistas y otros}

Escobar, A. Globalización, Desarrollo y Modernidad. (En: Organización de Estados Iberoamericanos para la Educación, la Ciencia y la Cultura. Recuperado de http://www.oei.es/salactsi/escobar.htm.

Ferguson, F. (2009) Curador Exposición: Francis Alys, Política del Ensayo Mayo 27 - agosto 17 de 2009. Biblioteca Luis Ángel Arango de Banco de la República, Casa Republicana, pisos 1 y 2 con el apoyo del Museo Hammer Francis Alÿs, política del ensayo. Recuperado de http://www.banrepcultural. org/adjuntos/francis-alys-politica-del-ensayo.pdf.

Galeano E.Los hombres tienen miedo a la mujer sin miedo. Diario Público, Madrid España, 08 de septiembre de 2010. Recuperado de http://www.publico.es/internacional/335504/eduardo-galeano-loshombres-tienen-miedo-a-la-mujer-sin-miedo.

Garrido, M. Erotología de los sentidos: el flâneur y la embriaguez de la calle En: Revista de Filología Románica. Anejo V 2007. CD Jóvenes investigadores Los sentidos y sus escrituras.

"Hábitat Habitar". Texto redactado con base en una ponencia presentada en la Sexta Reunión del Programa Universitario de Medio Ambiente organizada por la UNAM, 13 de octubre de 1997.

Popeanga, E. (2010), Modelos urbanos: de la ciudad moderna a la ciudad postmoderna. Revista Ángulo Recto. Revista de estudios sobre la ciudad como espacio plural. 2 (2) Recuperado de http:// pendientedemigracion.ucm.es/info/angulo/volumen/Volumen0/articulos01.htm).

Turner, V. (1988). «The Antropology of Performance». Performing Arts Journal. Recuperado de: http: / /www. uia. $\mathrm{mx} /$ actividades/publicaciones/iberoforum/6/pdf/davidl.pdf.

Revista Fedro. (2009, 8 de marzo). Revista de estética y teoría de las artes.

Revista Pliegos deYuste ( 2009) No. 9 -10 Revista de cultura, ciencia y pensamiento europeos. Cáceres.

Recibido: abril 15 / Aprobado: junio 1 de 2014 